\title{
LOS ABOGADOS Y EL DERECHO: SU COMPROMISO FRENTE A LA CORRUPCIÓN
}

\author{
THE LAWYERS AND THE RIGHT: \\ YOUR COMMITMENT TO CORRUPTION
}

Jorge LUIS GodenzI Alegre* MILLITZA FRANCISKOVIC INGUNZA**

* Abogado, con estudios concluidos de Magister y Doctorado en la Universidad de San Martín de Porres. Catedrático Universitario. Profesor Investigador. Dicta los cursos de Derecho Romano y de Historia General del Derecho en las Universidades de Lima, San Ignacio de Loyola y Universidad Ricardo Palma. Ha escrito Libros de Derecho Romano. Articulista en revistas especializadas.

** Doctora en Derecho, Magíster en Derecho Civil y Comercial, Abogada por la Universidad de San Martín de Porres. Docente nombrada de la Universidad Femenina del Sagrado Corazón, dicta los cursos de Derecho Ambiental y Derecho Internacional Público. Responsable Académica el CEADES - Círculo de Estudios en Ambiente y Desarrollo Sostenible. Coordinadora de la Unidad de Investigación en la Facultad de Derecho de la Universidad Femenina del Sagrado Corazón.

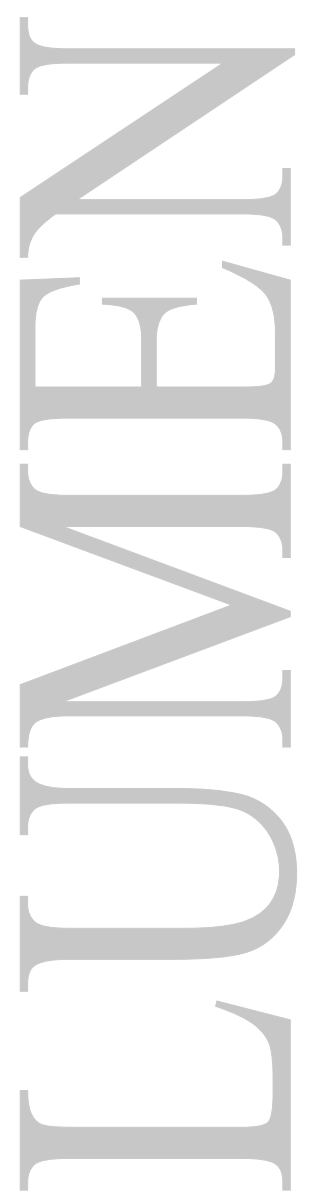




\title{
LOS ABOGADOS Y EL DERECHO: SU COMPROMISO FRENTE A LA CORRUPCIÓN
}

\author{
THE LAWYERS AND THE RIGHT: YOUR COMMITMENT TO CORRUPTION
}

Jorge Luis Godenzi Alegre

Millitza Franciskovic Ingunza

\begin{abstract}
RESUMEN
El presente artículo esboza las coordenadas en las que se ubica el engendro social de la corrupción, fenómeno que inmediatamente se le asocia con el mal por las consecuencias perniciosas que produce en la conciencia moral de los individuos en particular y en la moralidad de una Nación en general. Y ante esta patología social, si bien es cierto que los abogados hemos contribuido en combatirlo con la ley y la judicatura, también es verdad que poco es lo que hemos aportado en ofrecer formulas teóricas eficaces que contribuyan a su conjura definitiva.
\end{abstract}

\section{PALABRAS CLAVE:}

Abogacía - Ejemplaridad - Corrupción - Valores Éticos - Justicia - Responsabilidad Social - Historia - Leyes

\begin{abstract}
This article outlines the coordinates in which the social engendro of corruption is located, a phenomenon that is immediately associated with evil by the pernicious consequences that it produces in the moral conscience of individuals in particular and in the morality of a nation in general. And in the face of this social pathology, while it is true that lawyers have helped to combat it with the law and the judiciary, it is also true that little is what we have contributed to offer effective theoretical formulas that contribute to their final conspiracy.
\end{abstract}

\section{KEY WORDS:}

Advocacy - Exemplary - Corruption - Ethical Values - Justice - Social Responsibility - History - Laws

\section{Introducción.-}

A pocos meses antes de morir el pensador polaco, Zygmunt Bauman, lanzó la siguiente advertencia: "O la humanidad se da las manos para salvarnos juntos o, si no, será la entronización de la gran corrupción y el de la venalidad universal en el que los conceptos más venerados como la verdad, la justicia y la honestidad serán convertidas en mercancías públicas". Pues no cabe duda alguna que estamos viviendo ese tiempo. Una corrupción enquistada en la clase política y en el sistema de justicia, que traspasa los límites de la legalidad, que es lo que acaba de desatar la trama de Odebrecht, gigantesco caso de sobornos y adjudicación de obras públicas que facilitaron la corrupción que hoy se ha destapado, y que no ha tenido precedentes en la historia de nuestro país.

Es indudable que hemos ingresado a un peligroso escenario en el que el telón de fondo es la pérdida de autoridad moral y la persistente burla a las instituciones. Se está afianzando el desencanto y la frustración y la falta de vergüenza. Sin embargo, a pesar de esa lacerante realidad, también nos rodea la decencia, la ejemplaridad y el sano intento por generar cambios, desde las universidades y en particular de aquellas que tienen abolengo cristiano.

Para aportar nuevas reflexiones, sobre este enmarañado asunto, es que nos proponemos delinear algunas ideas en torno a esta patología social y lanzar un desafío respecto de la la inmensa responsabilidad social que tenemos los profesionales del derecho. 
Es evidente que el ejercicio de la actividad pública desde el aparato estatal ha olvidado la decencia, la conducta digna y la honestidad ante el país y la propia conciencia. Los valores éticos que inspiran a los hombres de bien, hoy parecen olvidados; la viveza criolla es alabada y festejada cínicamente, en tanto la práctica de las virtudes sociales y morales son desafortunadamente mal vistas.

Esta circunstancia es la que nos impulsa a la necesidad de refundar una ética de la responsabilidad que se enraíce en nuestro quehacer profesional. $O$ asumimos juntos responsablemente este enfrentamiento o en su defecto tendremos que recorrer aquel camino sin retorno con el que nos instruía Zygmunt Bauman.

En consecuencia, este apremiante tema va a ser abordado auxiliado por otras disciplinas y al hacerlo es indispensable tratar de ubicar estos tópicos en las condiciones históricas legales y culturales en que lo hemos analizado, y tendremos, en este caso, que rememorar algunos episodios de nuestra zarandeada historia; es decir situándolos en una fenomenología del espacio y del tiempo. Por esta razón, nuestra línea argumentativa estará dividida en tres partes: en la primera, dedicada al enfoque, muy personal por cierto, en tratar de explicar qué es la corrupción y cómo incide en nuestra población, a partir de algunas claves de la historia y de unos caracteres de tipo cultural y orgánico que subyace todavía en nuestro organismo social; la segunda parte, estará centrada a la función social que cumplen los abogados en su peregrinaje histórico y el importantísimo valor ético de la justicia con la que el abogado siempre estará intensamente comprometido; y por último, y como desafío que habremos de asumir, destacar el papel rector que debe cumplir la educación, la familia y el ejemplo de la vida de algunos ilustres abogados que ocupan sitio de honor y de excepción en el afán de redimirnos de ese espantoso fenómeno social que no solo sufre nuestro país sino que se ha extendido a escala planetaria.

Procederemos entonces a enlazar con la tradición neo-humanista que algunos discípulos de Erich Fromm han recuperado para el debate teórico que actualmente se libra entre partidarios y detractores de la modernidad y de la postmodernidad. El hombre contemporáneo vive —parafraseando a McLuhan - en "una aldea global" donde las personas no pueden entregarse a la práctica de un individualismo exacerbado; sino que deben librar solidariamente un compromiso en la defensa de principios y valores éticos universales que dignifiquen a todos los seres humanos; sólo así, se podrá hablar con propiedad de la persona como algo realmente sagrado, en clara alusión a la célebre sentencia que en su día inmortalizó Séneca: homo, sacra res homini.

Es indudable que vivimos una privilegiada época de permanentes cambios y contradicciones. En efecto, la sociedad contemporánea, a la que algunos autores califican como "la sociedad tecnológica" y otros como "la sociedad informática" es el ámbito donde, junto a esos grandes progresos de la racionalidad y de la ciencia, coexisten ámbitos importantes en lo público y en lo privado dominados por la necedad, por el simplismo y por la vulgaridad intelectual. Como dice Noam Chomsky, es sorprendente la "fascinación que parecen tener las ideas incoherentes". A veces los medios de comunicación se encargan de difundirlas e incluso de alentarlas, y responsables políticos o líderes de opinión de dotarlas de autoridad y de solvencia. En otros ámbitos, escuchamos a diario lugares comunes que se repiten con grandes palabras como si estuviéramos ante aportaciones ingeniosas. La extensión con que la prensa en general ha tratado esos asuntos nos permite percibir la amplitud del eco de esas palabras. Y uno de esos vocablos muy trajinados y tan poco analizados es el de la corrupción.

Engendro social que con razón inmediatamente lo asociamos con el mal, por las consecuencias perniciosas que produce en la conciencia moral de los individuos en particular y en la moralidad de una Nación en general. Y ante este fenómeno, si bien es cierto que los abogados hemos contribuido en combatirlo con la ley y la judicatura, también es verdad que poco es lo que hemos aportado en ofrecer fórmulas teóricas eficaces que contribuyan a su eliminación definitiva. 
Pareciera, como opinan algunos, que el derecho, como orden rector de la convivencia, no tuviera nada que decir ante este problema que enfrenta la sociedad; pues muchos nos contentamos con escarbar en los significados posibles o imposibles de tal o cual artículo de los Códigos o de la legislación, y ahí queda nuestro menester. ¿Es que frente a la corrupción el derecho, además de la represión, no puede aportar otras fórmulas?, ¿Es que los juristas no son capaces de procesar evento tan miserable desde las coordenadas de nuestra disciplina? No faltarán los que digan que estudiar la corrupción desde la óptica jurídica equivale a perder cualquier rastro de cientificidad, puesto que el análisis jurídico debe permanecer, como bien lo enseñó Kelsen, "puro" y limitarse al mundo de las normas jurídicas, sin hacer caso de otros fenómenos "extra-jurídicos".

Frente a ese escenario, la sociedad naturalmente nos emplaza para que presentemos nuevas ideas, propuestas y no sutiles interpretaciones de la ley porque perfectamente también sabemos que la corrupción, de por sí ya constituye la negación del derecho por pervertir en grado sumo al valor de la justicia y de los otros valores éticos, sin los cuales, como inmejorablemente entendemos, no es posible concebir ninguna tutela efectiva de los bienes jurídicos.

Bien, entonces empezaremos formulando la siguiente pregunta y respondiéndola por supuesto ¿Qué es la corrupción? Diderot contestaría "la corrupción consiste en la ignorancia de las leyes escritas y en la observancia de aquellas inconfesables". Modestamente, entendemos por corrupción la acción de dañar, pervertir, depravar y echar a perder manipulativa y utilitariamente a alguien con propósitos malsanos, alterando y trastocando su identidad, propiciando, consciente o inconscientemente, la complicidad en el logro de finalidades perversas. Este accionar va a ir contaminando y desfigurando gradualmente la conciencia moral del individuo.

La conciencia moral, para entendernos, es aquel estado de cosas en el que perfectamente distinguimos lo que es bueno y malo, justo e injusto, honesto y deshonesto, la verdad y falsedad, conveniente e inconveniente, veracidad y mentira, lo sublime y grotesco, lo correcto e incorrecto, el bien y el mal y todos los valores éticos (la vida, el bien, la justicia, la libertad, la solidaridad etc.) que existen entre estos dos polos; y eso es lo que nos permite juzgar, es decir, formarnos juicios acerca del valor de los medios que empleamos, motivos y fines de las acciones que cada persona en la vida dispone. Por eso Kant la llamó "razón práctica" en la medida que es capaz de apreciar el valor de las acciones y el poder decidir entre varias posibilidades en razón de que uno, al amparo de la libertad, es capaz de elegirlas y de dirigirlas personalmente.

La moralidad en cambio es un hecho social que comprende el comportamiento de todas esas personas con el conjunto de principios rectores, conceptos morales, virtudes e ideales que predominan en la colectividad. La moralidad, que es socialmente dinámica siempre subyace en el subconsciente del pueblo. Es, empleando una metáfora, nuestra casa moral y colectivamente estamos orientados por ella.

¿Dónde incide la corrupción básicamente? En deteriorar, enfermar, descomponer, con fines espurios y nefastos la conciencia moral de los individuos, pudiendo ser éstos dirigidos y cultivados con fines corruptos. Esta identidad corrupta elimina los valores creativos a favor de una supuesta ética del éxito que va a producirle al individuo un agonizante entredicho con la moralidad imperante; $y$, por supuesto, eso va a crear las condiciones para que todos tengamos potencialidades de corrupción. En esas condiciones somos factibles de corromper o de que nos corrompan; desde el punto de vista conceptual existen dos instancias que hay que diferenciar. De un lado, corromperse activamente en determinado momento (acto corrupto) sin que necesariamente la corrupción se haga crónica e irreversible, sino transitoria; esta instancia no involucra totalmente la identidad de la persona con esa lacra. De otro lado, se da el caso que la persona no solamente se corrompe, sino que continúa siendo corrupta, asume y encubre la corrupción en sí misma, tratando de corromper a otros (estructura corrupta). 
En nuestro país, a lo largo de su historia, apareció la corrupción muchas veces; fue perseguida y luego olvidada para que así volviera a aparecer. Ha sido siempre un círculo vicioso que se encuentra instalada y del que habrá que salir para poder ganar esta batalla. La corrupción ha crecido, además, bajo la sombra de la mal entendida tolerancia y cuando llega a límites exagerados recién se reacciona contra ella, generalmente sancionando a los pequeños corruptos.

¿Cómo se inicia este engendro social? Los elementos predisponentes, dicen algunos investigadores, son los que corresponden a la herencia y a la constitución de la Nación. Los factores determinantes, en el caso de nuestra sociedad, serían aquellos provenientes de todo ese proceso de implantaciones jurídicas culturalmente traumáticas que inevitablemente produjo confusiones, malentendidos y equívocos que sufrimos a partir de la conquista hasta haberse instalado en el Virreinato toda su institucionalidad.

Recordemos en la época republicana, en sus continuidades y discontinuidades gira en torno a la exclusión, violencia y corrupción como las dimensiones más devastadoras de las formas de gobierno estatal y de los modos de convivencia que se arraigaron aún más a partir de nuestra independencia política.

Merece que evoquemos algunos episodios de nuestra historia para demostrar esa afirmación. Es el caso de Riva Agüero, primer Presidente peruano, que fue declarado traidor por Bolívar y casi fusilado cuando se le descubrió actos túrbidos lindantes con la corrupción y que logró un arreglo negociado con las fuerzas coloniales, a espaldas del comando patriota. Por ese y otros acontecimientos de carácter político Simón Bolívar expidió ese famoso Decreto por el cual se sancionaba con la aplicación de la pena de muerte contra los funcionarios corruptos.

Otro caso ocurrió a mediados del siglo XIX, gracias al ingreso proveniente de la explotación del guano. El gobierno de Ramón Castilla decidió que había llegado el momento de que el Estado peruano pagara la cuantiosa deuda interna acumulada desde 1820 debido a los cupos y confiscaciones solicitados para afrontar las guerras de independencia y los conflictos de los primeros años de la República. Lo hizo a través de las leyes de Consolidación entre 1847 y 1853 en el gobierno de Echenique estableciéndose un padrón de acreedores del Estado con deudas que superaban los 20 millones de pesos. Fue una manera muy grosera y escandalosa en la que algunos corruptos capitaneados por Rufino Echenique se repartieron las riquezas del guano. Se comenta que en ese proceso hasta llegaron a falsificar expedientes con la firma de José de San Martín para hacer aparecer deudas fantasmas del Estado peruano.

Sobre este triste episodio están las palabras de un hombre público, abogado honesto y olvidado Gil Antonio de Toledo, Presidente de la Corte Central de Acusación de esa época contra el gobierno de Pezet que decía lo siguiente: "Desde Santa Cruz a Salaverry, desde Castilla hasta Echenique y Pezet se cometieron grandes crímenes políticos, se infundieron profundos daños al honor y al derecho de la República y estos delitos, a pesar de su enormidad, quedaron sin escarmiento porque ninguno de sus autores ni cómplices recibieron la sanción que merecían......"

Como anécdota y clara demostración de que cuando la corrupción se expande, ésta se inyecta transformando la moralidad, en su archiconocido Diccionario de Peruanismos don Juan de Arona incluye la palabra "consolidado" como peruanismo histórico-político-fiscal para referirse a los enriquecidos con la ley de consolidación de la deuda interna.

Algo análogo se repite en los decenios del 60 y 70 y también con el pretexto de alguna ley, la de obras públicas o ferrocarriles y la de expropiación de salitreras. Prácticamente a los actos corruptos, de manera simulada, se les dio carta de ciudadanía. 
En aquella época, también se consagró la impunidad. Era el Perú, en aquel entonces, como refiere Basadre, el país más impunista de América. Ya lo había dicho Piérola: En el Perú nada quita ni da honra; y un gran periodista nacional don Andrés Avelino Aramburú decía que los peruanos estábamos acostumbrados, al final de cada gobierno, a bañarnos en las aguas del Leteo para perder la memoria. Con ese concepto moral daba lo mismo haber procedido bien o mal; justa o injustamente. O sea existía ya una turbada conciencia moral.

Resulta entonces que esa fue la conformación de nuestra estructura moral, habiéndose debilitado seriamente todos los principios, conceptos e ideales que conformaban la moralidad; todos esos vectores consiguientemente fueron gradualmente deshilachándose.

La moda, la permisividad, el relativismo moral son las pautas vertebrales básicas en el que los ciudadanos del presente van a seguir los vaivenes de lo conveniente y oportuno y con esa actitud se van a encubrir indirectamente actos de corrupción; existiendo una predisposición, casi orgánica, compartida por la mayoría de los individuos para facilitar la corrupción y éstos queden impunes. A continuación, se repasan algunos dichos que desafortunadamente son frecuentemente escuchados en nuestro país y que constituyen claros ejemplos de ese reblandecimiento de nuestra ya precaria moralidad. "Denunciar a los corruptos es actuar como delator". Muchas personas se niegan a denunciar a los corruptos porque consideran que haciéndolo actúan como delatores; este comportamiento será, qué duda cabe, moralmente cuestionable. Si los corruptos consiguen que las personas honestas no los denuncien, entonces la corrupción ha triunfado porque logrará su mayor éxito: la impunidad, y esa es la mejor garantía para que la corrupción se desarrolle y continúe su propagación.

Otra frase, es aquella que se refiere al que "Roba pero hace obra". Muchos piensan que, si el gobernante hace obras, si gobierna dando muestras de preocupación por el pueblo, se le puede perdonar que sea corrupto. Esta forma de pensar también es cómplice de la corrupción porque se acepta la inmoralidad con tal de que el gobernante haga lo que uno cree que debe hacer o incluso se aprueba porque sus decisiones implican algún beneficio. "Hoy por ti, mañana por mí" esta otra frase es tan conocida que incluso figura en un conocido vals criollo de antaño y se utiliza cuando el funcionario público aprovecha el poder haciendo favores a ciertas personas para que se los retribuyan; es indudable que se está ante una forma de corrupción porque en el fondo se está beneficiando del cargo público para obtener beneficios personales. Luego, el hecho de que justifiquemos el ejercicio del poder como un beneficio, como un logro personal, o como un ascenso en la vida es verdaderamente una primera forma de corrupción porque se ejerce el cargo de manera esencialmente equivocada.

En consecuencia, cuando en la sociedad las personas no denuncian la corrupción lejos de ser honestas, son sus principales encubridores o cómplices porque protegen a los corruptos. Por ello, considerarse delator cuando uno denuncia la corrupción es un rasgo cultural que implica que estamos recobrando el interés en rescatar de nuestra conciencia moral los principios rectores que conduce la moralidad de nuestra Nación.

La corrupción deberá ser severamente sancionada y siempre, sin excepciones porque es la mejor forma de evitarla. En efecto, quien incurre en ella, generalmente lo hace porque cree o está seguro que nunca será descubierto y sancionado. Si pensara lo contrario, se abstendría y buscaría un mejor medio a fin de obtener su propósito.

Las formas y los alcances de la corrupción, como hemos visto, son muy amplias que para combatirla es necesario rearmar nuestras conciencias morales, corrigiendo nuestros errores porque cuando el sentimiento moral de un pueblo no encuentra justicia, ese empeño se corrompe transfigurándose en deseo de venganza. Encontrándonos ante una sociedad vengativa... y la venganza no puede crear humanidad y eso contradice gravemente el homo, sacra res homini planteado por Séneca. 
En la segunda parte de este artículo, respecto del quehacer del abogado, nos va a alentar rememorar algunos pensamientos de don Ángel Ossorio, ex decano del Colegio de Madrid, autor de una celebérrima obra: "El alma de la toga". Él sostenía que la abogacía no es sólo una consagración académica, sino una concreción profesional en la que no solamente el abogado debe dedicar su vida a dar consejos jurídicos sino a pedir siempre que se haga justicia; y afirmaba que un abogado, con rectitud de conciencia es mil veces más importante que el tesoro de los conocimientos que pueda acumular. La abogacía es un apostolado porque: primero, el abogado debe ser bueno; luego, ser firme; después, ser prudente; la ilustración viene en cuarto lugar; la pericia en el último. El abogado, revelaba este profesor español, no se hace con el título de Licenciado, sino con las disposiciones morales adquiridas a costa de trozos sangrantes de la vida. Efectivamente eso es así y está erigido desde el memorable Digesto de Justiniano, el advocatus, era el hombre llamado para un asunto, quería decir patrono, defensor; hombre de consejo y versado en la erudición del derecho y en la crítica de las leyes, según los principios de la filosofía y de la moral.

Luego, la abogacía en la alta edad media cristiana fue considerada como "colaboradores del reino de Dios", oficio vinculado directamente con una nueva concepción ética basada en los principios del cristianismo. Hoy acaso haya perdido, en cierto modo, su dignidad y jerarquía. Pero es indiscutible que dos son las raíces de esta noble profesión: la vocación que fluye de lo más hondo del alma; y el núcleo de valores éticos que constituye su objetivo. El factor objetivo de la profesión siempre ha estado constituido por ese mundo de valores que forma el contenido específico de su función; y entre los valores éticos sobre los cuales se inspira es el de la justicia el valor fundamental que la determina en el complejo mundo del organismo social y le da, por supuesto, fundamento a su quehacer cotidiano; y cuando el abogado logra que la justicia se materialice se está logrando la plena realización profesional. Por el contrario, la falta de vocación e indiferencia frente a ese esencial valor ético los conducen definitivamente a la inseguridad y a un rotundo fracaso.

Por ese motivo, el auténtico hombre de derecho se ha caracterizado siempre por un constante afán de justicia y eso los podemos comprobar nosotros, los profesores, cuando penetramos en el alma de nuestros estudiantes y generalmente encontramos en ellos que la justicia verbalizada - no procesada lógicamente de manera académica - es lo primero que está impreso en su carácter. Sabemos perfectamente que la vivencia de la justicia presenta dos formas diferentes: la justicia ideal y la justicia positiva, considerada como seguridad jurídica. Radbruch decía que el hombre de derecho lego o profano se orienta siempre más hacia la justicia, el hombre de derecho jurista, más hacia la seguridad; hablando en lenguaje de Spranger aquél es más idealista del derecho, éste más formalista del derecho. Ambas formas de justicia se complementan porque la justicia como todos los valores éticos presentan, como hemos venido diciendo, entre sus caracteres la polaridad. Cuando no se ofrece ese equilibrio, entre la tendencia hacia una justicia ideal y el sentido de seguridad que se identifica con la justicia positiva, surgen tipos degenerados como el fanático de la justicia estilo Robespierre que quiso instalar un gobierno radical de la virtud y ya sabemos cómo terminó. La otra justicia la lega, pero no por eso menos virtuosa, es aquella a la que ejemplificándola se refiere nuestro don Manuel González Prada en sus "Horas de Lucha" de Mariano Amézaga, quien lo describe así:... "no fue sólo un escritor sincero y viril, sino un abogado de honradez proverbial, un verdadero tipo en la más noble acepción del vocablo. Si un mal litigante pretendía encomendarle la defensa de algún pleito injusto, Amézaga le desahuciaba suavemente: "Amigo mío, como usted carece de justicia, yo no le defiendo". Si la causa le parecía justa, se encargaba de la defensa; pero las más veces le sucedía que no le pagaban los honorarios o que en el fragor de las peripecias forenses el litigante le decía socarronamente: "Señor doctor, valgan verdades, acabo de saber por el reverendo padre que usted ha publicado un libro contra los dogmas de nuestra santa religión; y yo, como buen católico, no puedo seguir teniendo de abogado a un hereje"..." Definitivamente, y como apunta el abogado Mariano Amézaga resulta que para proclamar a su eventual litigante que no le asistía la justicia, era, presumo, su declaración como consecuencia de aquella lucha interior al cual hemos venido denominándolo, en esta exposición, como conciencia moral. A este 
respecto, cedámosle la palabra nuevamente a Radbruch: "El proceso moral se desarrolla, no entre los hombres, sino en el seno del hombre individual, en una silenciosa polémica entre los apetitos y la conciencia, entre la parte grosera y corrompida y la parte mejor o ideal de nosotros mismos, entre la criatura y el Creador, en el fondo de nuestro propio pecho. En la Moral se halla el hombre -como Cristo en el Desierto- en sublime soledad consigo mismo, sometido únicamente a la ley y al tribunal de la propia conciencia". Por eso fácilmente resulta explicable la conducta del Abogado Amézaga de negarle patrocinio al litigante, por carecer de justicia; la búsqueda de la justicia era su virtud por haber sido hombre justo y ese quizás puede ser el designio del abogado del futuro que queremos formar: Que sean justos y honrados.

Ocurre que los abogados también cumplimos una función social cuando, desde la ladera en que nos ubiquemos, orientamos la desbordante vida de los pueblos dentro de los cauces de la norma legal; para organizar las instituciones desfiguradas por obra de intereses y pasiones; para rescatar y destacar los valores éticos oscurecidos o negados por el interés desmesurado en la maximización de los beneficios y el progreso que se evidencian en el crecimiento a ultranza del mercantilismo; para inculcar principios frente a su permanente negación.

La abogacía, es una profesión cuyo sustento teórico se halla en la ciencia más alta de todas las cosas divinas y humanas, como denominó Ulpiano a la Jurisprudencia, y cuyo ideal práctico consiste en que la conducta siga derechamente por los caminos de la vida. He aquí la dignidad de esta profesión nuestra, fundada en un dogma que no debemos jamás olvidar: la fe en el homo, sacra res homini.

Todo buen abogado y abogada debemos hacer nuestras esas inmortales palabras que Platón pone en labios de Sócrates en el Gorgias: "El espíritu, dice (del buen orador, del buen abogado) estará constantemente ocupado en buscar los medios para hacer que nazca la justicia en el alma de sus conciudadanos, y que se destierre la injusticia; en hacer germinar en ella la templanza y descartar la intemperancia; en introducir todas las virtudes y excluir todos los vicios".

"Dad a un hombre, ha escrito Giurati, todas las dotes del espíritu y todas las del carácter, haced que todo lo haya visto, que todo lo haya aprendido y retenido, que haya trabajado durante 30 años de vida, que sea en conjunto un literato, un crítico, un moralista; que tenga en conjunto la experiencia de un viejo y la infalible memoria de un niño, y tal vez, con eso formaréis un abogado completo".

En su función política, la abogacía ha sido un factor importante y decisorio en la elaboración de espléndidas y aún deslumbrantes arquitecturas jurídicas que por ejemplo se reflejan en las catorce Constituciones políticas que hasta la fecha han regido a nuestro país; códigos, tratados teóricos de doctrina, jurisprudencia, lo mismo que los volúmenes llenos de ilustración y conocimientos que contienen las resoluciones judiciales, principalmente las del Tribunal Constitucional, no son otra cosa que una suerte de metales que solamente hacen ruido si pierden o siquiera disminuyen su inspiración con el sentimiento moral. Esta conexión, semejante a un cordón umbilical, es lo que al final de cuentas las alimenta y lo que le da sentido moral a las leyes y las decisiones judiciales. El problema principal detrás de esa desarticulación de leyes y justicia con la realidad es la corrupción; y entonces dejan de ser útiles. Las leyes, Códigos y Tribunales, aún en sus deslumbrantes estructuras formales, racionales y abstractas, no van a resolver por sí solos conflictos reales ni van a producir justicia mágicamente si no están acopladas con los valores éticos.

Por consiguiente, un derecho corporalmente orientado, dispuesto en dirección a ese valor ético o bien social que denominamos justicia, deberá contribuir a forjar una sociedad donde ese valor esté al servicio de todos y la misión de los abogados es buscar el enlace de ese mundo precario de acontecimientos con aquel mundo del deber ser del derecho que es la justicia, con lo cual siempre el auténtico sentimiento jurídico estará radicalmente vinculado con el sentimiento moral. 
Y, por último, estimo, a la luz de esta elucidación, que para batallar contra la corrupción no solo es suficiente la dación de leyes inflexibles, ni creando organismos especializados del Estado para que se la enfrenten. Consideramos que serán apenas medidas meramente efectistas que lo que va a producir es que esta lacra social se repliegue y vuelva a aparecer después con mayor desenfado como ha venido ocurriendo a lo largo de toda nuestra historia. Para extirparla definitivamente se requiere desarticularla de nuestro organismo social y ese propósito, desde nuestro modesto punto de vista, sólo se logrará a nivel de educación y de vidas ejemplares: auténticos prototipos de ciudadanos.

La educación, al ser revalorada desde la familia evitará primero de que existan menos madres e hijos abandonados y para que también desde los colegios se empiece con la enseñanza de los valores morales.

El ejemplo de vida, o sea la conducta moralmente rectilínea es muy importante para combatir la corrupción que, como se puso de manifiesto en líneas precedentes, antes se encuentra dispersada en el mundo. Existe un precedente foráneo que me voy a permitir traerlo a colación, y al tomarlo en cuenta me va a facilitar secundar la tesis de que los gestos y conductas de ciudadanos honestos a veces son socialmente determinantes para hacer frente a esta deplorable aberración social.

Actualmente en el debate público se echan cada vez más de menos voces que transmitan ejemplaridad y honestidad, referencias basadas en una autoridad de prestigio moral, que los antiguos griegos y romanos, fundadores de los primeros sistemas de gobierno participativo de la historia, llamaron semnotes o auctoritas.

El Renacimiento de Palermo, como se le ha llamado a ese episodio que aconteció en Italia y que conmovió al mundo en la década de los noventa, es lo que podríamos denominar como un claro ejemplo de cómo se enfrentaron dos eximios abogados y mejores magistrados contra la mafia siciliana: Giovanni Falcone y Paolo Borsellino. Jueces que tuvieron convicción, visión y sobre todo coraje para cambiar un estado de cosas que hasta ese entonces dominaba la mafia. El primero fue muerto junto con su esposa y tres de sus escoltas el 23 de junio de 1992 y el segundo el 19 de julio del mismo año.

El 23 de junio de 1992 fue asesinado el juez Giovanni Falcone, Director General del Ministerio de Justicia de Italia y símbolo viviente de la lucha contra la Mafia. Sus enemigos lo hicieron volar con una tonelada de explosivos, activados por control remoto; el vehículo blindado en que viajaba por la autopista Palermo-Trappani, a 20 kilómetros de la capital de Sicilia. Con el magistrado, que tres días antes había cumplido 53 años, murieron su esposa y tres agentes de su custodia. Cuatro meses antes Falcone había sido designado al frente de la flamante Dirección Antimafia (DIA). Y eso a pesar de que era un hombre "marcado" por la Cosa Nostra desde los años 80, cuando ya había comenzado a recibir amenazas de muerte. En 1987 mandó a la cárcel a más de 300 pistoleros luego del llamado "maxiproceso de Palermo". Y en junio de 1989 se había salvado por casualidad de un atentado mientras estaba de vacaciones en una playa siciliana en la costa del Mediterráneo.

"Existen fuertes puntos de unión entre los vértices de la Cosa Nostra y centros ocultos de poder que tienen otros intereses", declaró entonces. "Tengo la impresión que es éste el escenario más plausible si se quieren comprender las verdaderas razones que han empujado a alguno a asesinarme".

Un año antes de su muerte, el juez había publicado el libro Cosas de la Cosa Nostra, en el que denunciaba los vínculos subterráneos entre políticos y mafiosos. "Nadie me hará creer que algunos grupos políticos no están aliados con la Cosa Nostra - por convergencia de intereses - en el intento de condicionar nuestra democracia, todavía inmadura, eliminando a personajes incómodos para ambos". 
Miles de personas asistieron a la Catedral de Palermo para el funeral del magistrado, quien se había definido a sí mismo con las siguientes palabras: "Yo no soy Robín Hood, ni un kamikaze, ni un misionero. Soy sólo un servidor del Estado en tierra infiel". El 5 de diciembre de 1992, una niña colocó un mensaje en el árbol que se hallaba frente a la casa del magistrado en la capital de Sicilia: "No quisiste tener hijos. Yo hubiera querido ser uno de ellos", escribió la pequeña Luisa en una hoja de cuaderno escolar. Desde entonces "el árbol de Falcone", como se le conoce ahora, se cubrió de notas. "Dedico mi diploma a Giovanni Falcone, porque es el fruto de un trabajo limpio, sin la ayuda de "padrinos" ni recomendaciones. La Mafia será derrotada con pequeños gestos cotidianos", decía el mensaje de un universitario. Y alguien dejó esta frase: "Querido Don Giovanni: Gracias por habernos recordado que somos ciudadanos con pleno título y no un rebaño que lloriqueando pide asistencia y protección". El ex jefe del gobierno italiano, Giuliano Amato, apuntó: "Sería mejor vivir en un país donde los héroes ya no existieran, pero por desgracia aún los necesitamos". El Juez español Baltasar Garzón dijo de él: "Desde siempre he tenido a Falcone como un gran profesional y como un modelo de vida".

A Falcone le gustaba repetir las palabras de J.F. Kennedy: "Un hombre debe hacer aquello que su deber le dicta, cualesquiera que sean las consecuencias personales, cualesquiera que sean los obstáculos, el peligro o la presión. Ésta es la base de toda la moralidad humana".

El 19 de julio de 1992, Paolo Borsellino murió al explotar un coche bomba estacionado en la Via D'Amelio, Palermo. El atentado cobró, además, la vida de cinco policías. Un coche bomba explotó en Via d'Amelio en Palermo, delante de la casa de la madre del juez Borsellino, que murió junto con 5 personas de su escolta; y no habían pasado todavía dos meses desde el atentado mortal que sufrió su gran amigo. Hoy se consideran a Paolo Borsellino y Giovanni Falcone como dos de los magistrados más importantes asesinados por la mafia siciliana y se les recuerda como símbolos principales de la batalla que libró el Estado contra la Mafia.

En ellos, es admirable que hayan muerto sin haber traicionado sus convicciones en sus condiciones de abogados ejemplares y jueces honestos y por ello es que hasta ahora ambos ilustres abogados mantienen incólume su auctoritas. Y esa forma de tener convicción moral me parece que entre nosotros pasa por incidir en la educación que ineluctablemente deberá ser revalorada, desde la familia, pasando por la escuela y la Universidad, para que sus integrantes sean orientados en sus deberes cívicos y en la honestidad, con la enseñanza de la responsabilidad y el buen ejemplo.

Siempre es necesaria la ejemplaridad moral. Pero mucho más en las circunstancias actuales, cuando la corrupción alienta a su descreimiento. Es probable que parte de este problema se encuentre en nuestro sistema educativo que no ha sabido transmitir unos valores éticos indispensables para la formación de la persona. De allí que la franca enseñanza de esos valores generen fundadas esperanzas de que, en una Universidad, de raigambre cristiana, como la UNIFE se preocupen de sobremanera no solo en alcanzar la excelencia académica sino también en exaltar la honradez y el sentido de justicia. Ser honestos es una forma de garantizar la verdad y la transparencia de las acciones y ello supone una concordancia entre lo que se predica y lo que se hace.

Otro aspecto que contribuye efectivamente en la conjura de la corrupción es reconstruir nuestra tradición y memoria respecto de aquellos abogados, maestros del derecho que han sido y son también ejemplos de conducta moral. Es una magnífica ocasión donde nuestras certezas por la profesión se refuerzan doblemente. Ocurre que, para nuestro caso muy particular, fueron inolvidables Abogados y Maestros con quienes sentíamos lo que quiere decir, en la vida de la abogacía, ser colegas; este sentido que no se enseña, que se vive en la conciencia de todo abogado. Fueron ejemplos insuperables de lealtad. Es que los vínculos que nos unían a los alumnos - que en ese entonces éramos - con esos maestros, se asemeja mucho a los dulces vínculos de la familia; y nada se asemeja más a la paternidad de la sangre que la paternidad del pensamiento y del ejemplo. 
Ya se han deslizado varios años desde esa etapa de vida y nuestras sienes ahora se van tornando grises, pero la tristeza de esa inexorable transitoriedad humana se atenúa y dulcifica cuando ante los ojos de nosotros - ahora profesores - revivimos en la juventud de los alumnos las mejores virtudes que nos hemos propuesto transmitir para que esta cadena vital prosiga su periplo.

El mundo es grande, pero en último término nuestra vida se asienta en un metro cuadrado de tierra dijo el Maestro Eduardo Couture. Es cierto, nuestra vida al final se asienta en un metro cuadrado de tierra, pero queda el ejemplo que vale más que los códigos como lo expresó Calamandrei y queda además ese legado impalpable y eterno que se llama pensamiento. Nosotros que nos encontramos en un mundo de plastilina como el de hoy, donde la gente toma la forma del recipiente que le contiene, tenemos el urgente e imperioso deber de ser fieles a esos ejemplos que nos exigen firme adhesión a los valores éticos: de la vida, la justicia, la libertad y la solidaridad. Sólo siguiendo ese derrotero será posible que venzamos al flagelo de la corrupción; y nuestra Universidad, licenciada y mejor organizada como hoy se encuentra, estará en la vanguardia en esta responsabilidad y nuestra deslumbrante Facultad de Derecho y autoridades marcando el paso en el camino de renovación de la esperanza y confianza en el Derecho, como único medio para lograr la justicia; y entonces los abogados seremos los más consolados del mundo.

\section{REFERENCIAS BIBLIOGRÁFICAS:}

- Basadre, Jorge. (2005). Historia de la República del Perú. Novena Edición. Lima.

- Bauman, Zygmunt. (2007) Vida de consumo. Fondo de Cultura Económica. Madrid.

- Calamandrei, Piero. (2006) Elogio de los jueces escrito por un abogado. Editorial Reus. Madrid.

- Couture, Eduardo.(1999) Trayectoria y destino del derecho procesal civil hispanoamericano. Editorial Depalma. Madrid.

- Chomsky, Noam.( 2014) La propaganda y la opinión pública. Edición: Editorial Crítica. Barcelona.

- Fromm, Erich. (1998) Del tener al ser. Editorial: Ediciones Paidós. Argentina.

- Giurati, Doménico. (1878) Arte Forense. Roux \& Favale. Italia.

- González Prada, Manuel. (1924) Horas de Lucha. Editorial: Lux. Perú.

- Juan de Arona. (1975) Diccionario de Peruanismos. Editorial: DESA. Perú.

- Ossorio y Gallardo, Ángel. Los Hombres de Toga, en el Proceso de Don Rodrigo Calderón. Editor: Javier Morata. Madrid, 1934.

- Kant, Immanuel. Crítica de la razón práctica. Ediciones: Sígueme. Salamanca, 2014

- Kelsen, Hans. La teoría pura del derecho. Ediciones, Universidad Autónoma de México. México, 1982

- McLuhan, Herbert Marshall. Aldea global: Transformaciones en la vida y los medios de comunicación mundiales en el siglo XXI: la globalización del entorno. Editorial: Gedisa, Filial en México, 2015

- Platón. Gorgias o de la retórica. Obras completas de Platón. Ediciones: Medina y Navarro, Madrid 1871

- Radbruch, Gustav. Filosofía del derecho. Editorial: Reus. Madrid, 2008

- Séneca, Lucio Anneo. Sobre la brevedad de la vida. Editorial Gredos, Barcelona, 2011

- Viaggio, Gli Affari. Las últimas palabras de Falcone y Borsellino. Editorial: Chiarelettere. Milán, 2012

Fecha de recepción: 14 de setiembre de 2018

Fecha de aceptación: 30 de octubre de 2018 